\title{
The development and psychometric evaluation of a self-efficacy scale for practicing pelvic floor exercises
}

Cinara Sacomori, Fernando L. Cardoso, Isabela P. Porto, Nubia B. Negri

\begin{abstract}
Background: Self-efficacy has been shown to be a predictor of many health-related behaviors, including the practice of pelvic floor exercises with a focus on prevention or cure. Objectives: To describe the process of construction and the psychometric properties of the scale of self-efficacy for the practice of pelvic floor exercises (EAPEAP). Method: A cross-sectional study of validation was carried out with 81 from community and 96 postpartum women, $54.8 \%$ of them complained of urinary leakage. An exploratory factor analysis and internal consistency analysis was performed. To check predictive capacity, we analyzed the adherence at 3 months post - intervention and compared the scores of self-efficacy between adherent and non-adherent women. Reliability was analyzed by split half procedure. Results: The instrument showed $\alpha=0.923$, and revealed three factors: performance expectation considering the action, performance expectation considering the preparation for action and outcome expectations. These factors accounted for $65.32 \%$ of the total variance. The instrument was able to differentiate between women who adhere and have not adhered to the exercises $(\mathrm{U}=352, \mathrm{p}=0.013)$ and there was strong correlation between the two halves of the instrument (rho $=0.889$, $\mathrm{p}<0.001)$. Conclusion: The scale is a valid and reliable tool to measure self-efficacy to practice pelvic floor exercises.
\end{abstract}

Keywords: self-efficacy; pelvic floor; movement; validation studies; adherence.

\section{HOW TO CITE THIS ARTICLE}

Sacomori C, Cardoso FL, Porto IP, Negri NB. The development and psychometric evaluation of a self-efficacy scale for practicing pelvic floor exercises. Braz J Phys Ther. 2013 July-Aug; 17(4):336-342. http://dx.doi.org/10.1590/S1413-35552012005000104

\section{Introduction}

This study focuses on adherence to physical therapy and professional instructions because many therapeutic results are compromised due to low adherence and poor active participation to restore the desired patient function ${ }^{1}$. Similarly, adherence to exercise at home after physical therapy is essential to maintain results ${ }^{2}$.

According to Bandura ${ }^{3}$, self-efficacy beliefs are required for people to actively care for their own health. Self-efficacy is defined as "people's beliefs in their capability to exercise some measure of control over their own functioning and over environmental events"'. Thus, self-efficacy expectations eventually affect behavior. The environmental effects created by such behaviors also change self-efficacy beliefs ${ }^{3}$.

In the context of pelvic floor dysfunction (PFD), the exercises used to train the pelvic floor (PF) muscles are typically the first option in physical therapy. One systematic review indicated that physical therapy effectively reduces urinary symptoms in older women with urinary incontinence ${ }^{4}$. In addition, previous studies have suggested that a relationship exists between high self-efficacy and positive adherence rates to these treatments for urinary incontinence ${ }^{5-10}$.

Existing scales to evaluate self-efficacy with regard to practicing PF exercises (PFEs) have been developed and validated in other countries (e.g., the US $^{7}$, Taiwan ${ }^{11}$, Canada ${ }^{12}$, and Turkey ${ }^{13}$ ); however, none have been validated in Brazil. The present study evaluated the psychometric properties of the Self-Efficacy Scale for Practicing PFEs (SESPPFE).

\section{Method}

The present study employed a cross-sectional validation design.

\section{Participants}

This study consisted of 177 women, including 81 women from the general population (with or without PFD symptoms) and 96 postpartum women (54.8\% of whom complained of urinary leakage). The women from the general population were evaluated at the 
Network of Women Against Cancer (Rede Feminina de Combate ao Câncer) in Florianópolis, SC, Brazil, between September 2011 and March 2012. These women underwent a functional assessment of the PF muscles via a digital vaginal exam and were then instructed on how to perform daily PFEs that were meant to be preventive or curative. The postpartum (puerperium) women were at the Maternity Carmela Dutra, Florianópolis, SC, Brazil and received instructions concerning practicing the exercises in the maternity ward; however, only verbal instructions were provided, and the exercises were visually inspected.

This study excluded women who did not show signs of visible or palpable PF muscle contractions during a physical examination, those who were functionally illiterate, or those who refused to participate in the study.

The ethics committee of the Universidade do Estado de Santa Catarina (UDESC), Florianópolis, SC, Brazil (175/2011) and the Maternity Carmela Dutra (CAE: 0010.0.233.269-11), Florianópolis, SC, Brazil evaluated and approved this project. Patients provided consent by signing the free and informed consent form established by the above committees.

\section{Research instrument: Scale development}

The SESPPFE (Appendix 1) was developed specifically for this study based on the instructions provided by Bandura ${ }^{14}$. Other instruments in this field have been validated in other countries ${ }^{7,15}$. The barriers previously described for practicing unsupervised PFEs were also considered. Forgetfulness, a lack of time, the uncertainty of performing the exercises correctly, the perception that the exercises do not help, and the idea that PFEs were only important during pregnancy and postpartum ${ }^{16}$ were the major reasons that women provided to explain their low treatment adherence, their lack of interest or discipline with regard to performing the exercises, and their difficulties in integrating the exercises into their daily activities ${ }^{5,16-17}$.

The majority of scales tested in other countries were directed at women with $\mathrm{PFD}^{7,11-13}$. Thus, a new scale was developed rather than validating a scale that was previously described in the literature because the goals of the current study were to develop a scale that could be applied to women with or without incontinence and to identify their adherence to PFEs.

According to Bandura ${ }^{14}$, self-efficacy is composed of two dimensions: expected performance and expected results. The first refers to the judgments that one makes regarding an individual's behavior. The second addresses judgments regarding the possible outcomes of certain behaviors, both positive and negative ${ }^{18}$.

From this theoretical assumption, a pool of 16 items was prepared. The participants responded to these items on a scale ranging from 0 to 100 . Twelve items assessed expected performance, and four evaluated the expected results. The points allocated for each item were summed to calculate the selfefficacy score for practicing PFEs.

\section{Content analysis}

Four reviewers who are experts in female PFD or self-efficacy evaluated the scale. These reviewers validated the content of the instrument and offered suggestions to improve the phrasing of the items. Two reviewers requested that the following item be included: "How confident do you feel that you contracted PF to prevent leakage before coughing, sneezing, or strongly laughing." Therefore, the final scale included 17 items.

\section{Predictive ability}

To verify the scale's predictive ability, phone interviews were conducted with 89 women ( 48 from the general population and 41 postpartum women). This sample only includes the women who were successfully contacted via telephone approximately 3 months after the intervention. These women were asked whether they had performed PFEs in recent weeks.

\section{Internal consistency and dimensionality}

To evaluate specific psychometric qualities of the instrument, internal consistency and dimensionality analyses of the construct were performed using an exploratory factor analysis.

\section{Reliability}

Test-retest reliability was not assessed because self-efficacy changes with domain experience ${ }^{19}$. Thus, the understanding gained during PFEs should increase the self-efficacy beliefs of study participants. As an alternative to test-retest reliability, we performed the split-half technique in which the assessment is split in half and where one half is composed of the sum of the even items, and the other half is composed of the sum of the odd items.

\section{Data analyses}

The data were analyzed using descriptive statistics (frequency distributions, means, medians, 
and standard deviations). To analyze the predictive ability of the instrument, the Mann Whitney U test was used given the non-normal distribution of the data. Internal consistency was assessed using Cronbach's alpha coefficient, and the dimensionality of the construct was assessed using an exploratory factor analysis (i.e., principal component analysis, Varimax rotation). A significance threshold of $\mathrm{p}<0.05$ was adopted. Spearman's correlation was performed to infer the reliability of the test and ascertain the strength of the relationship between the two test halves.

\section{Results}

\section{Characterization of the participants}

In general, the study participants were white, lived with their partners, had received a primary to secondary level of education, and multiparous (Table 1). The average age of the women was 35.6 years $(\mathrm{SD}=13.9)$; the average age of the women in the general population was 45.8 years $(\mathrm{SD}=13.7)$, and the average age of the postpartum women was 27 years $(\mathrm{SD}=6.3)$.

\section{Internal consistency and dimensionality of the scale}

An exploratory factor analysis was performed to extract the principal components using Varimax rotation (Table 2). This analysis generated three factors that accounted for $65.32 \%$ of the total variance. The first factor (expected performance regarding an action) consisted of eight items that accounted for $48.25 \%$ of the total variance. The second factor (expected performance regarding action preparation) consisted of five items that accounted for $10.25 \%$ of the total variance. Finally, the third factor (expected results) consisted of four items that accounted for $6.81 \%$ of the total variance. The Cronbach's alpha coefficient for the scale was $\alpha=0.923$ ( $\alpha=0.840, \alpha=0.889$, and $\alpha=0.862$ for Factors 1,2 , and 3 , respectively).

\section{Predictive ability}

Women who continued performing the exercises 3 months after the intervention had significantly higher self-efficacy scores than those who did not perform PFEs during the same period $(\mathrm{U}=352 ; \mathrm{p}=0.013$; $\mathrm{Md}^{\text {adherent women }}=1,430$ and $\mathrm{Md}^{\text {nonadherent women }}=1,160$ ).

Table 1. Characterization of the participants.

All (n=177)

n

$\%$

\section{Marital Status}

Single

Married/stable Relationship

Divorced

Widowed

\section{Level of Education}

Elementary
Some high school
Graduation

Ethnicity

Caucasian

Parity

\begin{tabular}{lr} 
Nulliparous & 12 \\
Primiparous & 43 \\
Multiparous & 122 \\
\hline
\end{tabular}

Community women (n=81) Postpartum women (n=96)

n

20
48
9
4

45
29
6

69

11

1

6.8

24.3

68.9
$\%$

24.7

59.1

11.1

4.9

56.3
35.3
7.4

29

62

5

$\%$

n 
Table 2. Factor analysis of the SESPPFE.

\section{Item}

Perform PFEs by yourself

Remember to perform the exercises everyday

Perform the exercises at least three times a week

Include PFEs in your daily routine

Continue the exercises even when they do not show any noticeable results

Continue the exercises during vacation or travelling

Perform the exercises in the sitting position

Perform the exercises while standing

Contract your PF muscles before coughing, sneezing, or strong laughing to prevent urinary leakage

Continue the exercises even when your familial and personal responsibilities increase more than usual

Continue the exercises even when you have more activities to perform than usual

Continue the exercises even when another, more urgent, health problem exists

Perform the exercises even when another person says that it is not necessary (e.g., a family member or friend)

PFEs will prevent or improve health problems such as urinary leakage or bladder/uterine prolapse

PFEs will improve your sexual life

PFEs will improve your bodily perception

PFEs will benefit your health and well-being

$\alpha$ for each factor
0.761

Factor 1

Factor 2

Factor 3

0.483

0.792

0.826

0.697

0.661

0.646

0.410

0.565

0.637

0.850

0.821

0.781

0.804

0.777

0.840

0.889

0.862

$\mathrm{KMO}=0.900$. Bartlett's sphericity test $\mathrm{p}<0.001$.

Only 16 women (18\%) did not adhere to the exercises until the interview date; of these women, nine were from the general population, and seven were from the postpartum population.

The women from the general population had selfefficacy scores similar to those of the postpartum women $\left(\mathrm{U}=3740 ; \mathrm{p}=0.663 ; \mathrm{Md}^{\text {women in general }}=1,330\right.$, $\mathrm{Md}^{\text {postpartum }}=1,370$ ).

The two halves of the instrument were strongly correlated $(\mathrm{rho}=0.889, \mathrm{p}<0.001)$, which denotes an acceptable reliability.

\section{Discussion}

According to Bandura ${ }^{14}$, self-efficacy has two dimensions: expected performance and expected results. The three factors determined in the current analysis coincide with Bandura' ${ }^{14}$ theoretical proposal. However, the scale in this study divided expected performance into two components: the action itself and its preparation. Zengin and Pinar ${ }^{13}$ translated and validated a Japanese scale in Turkey and found the same three factors.

However, Broome ${ }^{7}$ found only two factors in the US, which matches Bandura's ${ }^{14}$ initial proposal. Chen ${ }^{11}$ also found two factors in Taiwan, called belief in the performance and muscle benefits of PFEs and belief in performing the recommended PFEs despite barriers. This differentiation suggests that Brazilian women might make a greater distinction between an action and the preparation to act (i.e., between predisposition and the desire to act).

No international consensus exists concerning a particular self-efficacy assessment, which complicates the study of cultural differences with regard to PFE adherence.

The current instrument achieved an acceptable level of internal consistency. Our scale differs from similar instruments ${ }^{7}, 11-13$ because it was tested among a heterogeneous sample (women with or without urinary leakage and those in postpartum). Therefore, 
this instrument is also applicable for women who do not have PFD symptoms but for whom exercises are suggested as a preventive measure. This area of practice is new for physical therapists who are part of multidisciplinary teams focusing on prevention and health promotion.

Self-efficacy is used to decide which actions are possible to perform while anticipating positive or negative results. Establishing a basis for action is important ${ }^{9}$. The current instrument differentiated between women who did or did not adhere to PFEs; therefore, it has an adequate predictive ability because theory suggests that self-efficacy beliefs are an important predictor of adherence to health-related behaviors $^{5-10,19-21}$.

Physical therapists often use health education strategies to change certain patient habits. The study of the issues that interfere with treatment adherence (e.g., a fear of falling among elderly patients ${ }^{22}$, the use of biomechanical insoles ${ }^{23}$, or practicing $\mathrm{PFEs}^{5-10}$ ) is becoming increasingly important.

Alewijnse et al. ${ }^{5}$ argued that a major predictor of PFE adherence is intention, a motive shaped by social influences, expectations, personal attitudes, and external variables. The present questionnaire addressed these items to determine its effect on treatment adherence. Thus, higher expectations regarding treatment should predict stronger motivations to adhere to treatment ${ }^{5}$. The application of this questionnaire (to treat or prevent urinary incontinence) provides information for the therapist regarding patients' levels of self-efficacy and motivation to perform the recommended therapy. This information is clinically relevant because it allows therapists to identify people with low self-efficacy and use strategies to improve a person's confidence with regard to the benefits of treatment.

The present study represents the first attempt to develop a scientific instrument to assess selfefficacy with regard to practicing PFEs in Brazil. Its application has the potential to improve its validity and reliability across different social and cultural contexts. Its use is also important with regard to planning and monitoring intervention projects of this nature, while avoiding high levels of participant evasion.

In conclusion, the SESPPFE is a viable and reliable measurement of the construct in question. This study is limited by its heterogeneous sample and the fact that only one group of women was evaluated using a digital vaginal exam. Therefore, we suggest that this scale is used and tested in future experiments.

\section{References}

1. Alewijnse D, Mesters I, Metsemakers JFM, Borne BVD. Strategies to enhance adherence and reduce drop out in conservative treatment. In: Bo K, Berghmans B, Morkved S, Kampen M, editors. Evidence-based Physical Therapy for the Pelvic Floor. London: Elsevier; 2007. http://dx.doi. org/10.1016/B978-0-443-10146-5.50013-7

2. Krüger AP, Luz SCT, Virtuoso JF. Home exercises for pelvic floor in continent women one year after physical therapy treatment for urinary incontinence: an observational study. Rev Bras Fisioter. 2011;15(5):351-6. http://dx.doi.org/10.1590/S1413-35552011005000006

3. Bandura A. A evolução da teoria social cognitiva. In: Bandura A, Azzi RG, Polydoro S. Teoria Social Cognitiva: Conceitos Básicos. Porto Alegre: Artmed; 2008.

4. Pereira VS, Escobar AC, Driusso P. Efeitos do tratamento fisioterapêutico em mulheres idosas com incontinência urinária: uma revisão sistemática review. Rev Bras Fisioter. 2012;16(6):463-8. http://dx.doi.org/10.1590/ S1413-35552012005000050.

5. Alewijnse D, Mesters I, Metsemakers J, Adriaans J, van den Borne B. Predictors of intention to adhere to physiotherapy among women with urinary incontinence. Health Educ Res. 2001;16(2):173-86. PMid:11345660. http://dx.doi.org/10.1093/her/16.2.173

6. Alewijnse D, Metsemakers JFM, Mesters IEPE, van den Borne B. Effectiveness of pelvic floor muscle exercise therapy supplemented with a health education program to promote long-term adherence among women with urinary incontinence. Neurourol Urodyn. 2003;22(4):284-95. PMid:12808702. http://dx.doi.org/10.1002/nau.10122

7. Broome BAS. Development and testing of a scale to measure self-efficacy for pelvic muscle exercises in women with urinary incontinence. Urol Nurs.1999;19(4):258-268. PMid:10889770.

8. Sampselle CM, Messer KL, Seng JS, Raghunathan TE, Hines SH, Diokno AC. Learning outcomes of a group behavioral modification program to prevent urinary incontinence. Int Urogynecol J Pelvic Floor Dysfunct. 2005;16(6):441-6. PMid:16237512. http://dx.doi. org/10.1007/s00192-005-1284-7

9. Messer KL, Hines SH, Raghunathan TE, Seng JS, Diokno AC, Sampselle CM. Self-efficacy as a predictor to PFMT adherence in a prevention of urinary incontinence clinical trial. Health Educ Behav. 2007;34(6):942-52. PMid:17456856. http://dx.doi. org/10.1177/1090198106295399

10. Chen S-Y, Tzeng Y-L. Path analysis for adherence to pelvic floor muscle exercise among women with urinary incontinence. J Nurs Res. 2009;17(2):8392. PMid:19516102. http://dx.doi.org/10.1097/ JNR.0b013e3181a53e7e

11. Chen S-Y. The development and testing of the pelvic floor muscle exercise self-efficacy scale. J Nurs Res. 2004;12(4):257-66. http://dx.doi.org/10.1097/01. JNR.0000387510.52243.c8

12. Tannenbaum C, Brouillette J, Korner-Bitensky N, Dumoulin C, Corcos J, Tu LM, et al. Creation and testing of the Geriatric Self-Efficacy Index for Urinary Incontinence. 
J Am Geriatr Soc. 2008;56(3):542-7. PMid:18179504. http://dx.doi.org/10.1111/j.1532-5415.2007.01572.x

13. Zengin N, Pinar R. Reliability and validity of the continence self-efficacy scale in Turkish women with urinary incontinence. Nurs Health Sci. 2012;14(3):277-84. PMid:22632069. http://dx.doi. org/10.1111/j.1442-2018.2012.00692.x

14. Bandura A. Guide to the construction of self-efficacy scales. In: Pajares F, Urdan T, editors. Self-efficacy beliefs of adolescents. Greenwich: IAP - Information Age Publishing. 2006, v. 5, p. 307-337.

15. Mâsse LC, Heesch KC, Eason KE, Wilson M. Evaluating the properties of a stage-specific self-efficacy scale for physical activity using classical test theory, confirmatory factor analysis and item response modeling. Health Educ Res. 2006;21(Suppl 1):i33-46. http://dx.doi.org/10.1093/ her/cyl106

16. Chiarelli P, Murphy B, Cockburn J. Acceptability of a urinary continence promotion programme to women in postpartum. BJOG. 2003; 110(2):188-96. PMid:12618164. http://dx.doi.org/10.1046/j.1471-0528.2003.02205.x

17. Borello-france D, Burgio KL, Goode PS, Markland $\mathrm{AD}$, Kenton K, Balasubramanyam A, et al. Adherence to behavioral interventions for urge incontinence when combined with drug therapy: adherence rates, barriers, and predictors. PhysTher. 2010;90(10):1493-506. PMid:20671098. http://dx.doi.org/10.2522/ptj.20080387

18. Bandura A. Social Foundantions of Thought \& Action - A Social Cognitive Theory. Englewood Cliffs: Prentice Hall; 1986.
19. Pajares F, Olaz F. Teoria Social Cognitiva e Auto-eficácia: uma visão geral. In: Bandura A, Azzi RG, Polydoro S. Teoria Social Cognitiva: Conceitos Básicos. Porto Alegre: Artmed; 2008.

20. Zinken KM, Cradock S, Skinner TC. Analysis System for Self-Efficacy Training (ASSET). Assessing treatment fidelity of self-management interventions. Patient Educ Couns. 2008;72(2):186-93. PMid:18534809. http://dx.doi. org/10.1016/j.pec.2008.04.006

21. Wangberg SC. An Internet-based diabetes self-care intervention tailored to self-efficacy. Health Educ Res. 2008;23(1):170-9. http://dx.doi.org/10.1093/her/cym014

22. Camargos FFO, Dias RC, Dias JMD, Freire MTF. Crosscultural adaptation and evaluation of the psychometric properties of the Falls Efficacy Scale - International Among Elderly Brazilians (FES-I-BRAZIL). Rev Bras Fisioter. 2010;14(3):237-43. PMid:20730369. http:// dx.doi.org/10.1590/S1413-35552010000300010

23. Guimarães C, Teixeira-Salmela L, Rocha I, Bicalho L, Sabino G. Factors related to compliance with biomechanical insole use. Rev Bras Fisioter. 2006;10(3):271-7. http:// dx.doi.org/10.1590/S1413-35552006000300004

\section{Correspondence}

Cinara Sacomori

LAGESC

Rua Pascoal Simone, 358, Coqueiros

CEP 88080-350, Florianópolis, SC, Brasil

e-mail: csacomori@yahoo.com.br 
Appendix 1. Self-Efficacy Scale for Practicing PFEs (SESPPFE).

Respond using the scale:

0

1020

30

40

50

60

70

80

90

100

Cannot under any

Moderately certain

circumstance

that I can

Highly certain

that I can

How confident do you feel that you can...

Confidence

Perform PFEs on your own.

Remember to perform the exercises every day.

Perform the exercises at least three times a week.

Include PFEs in your daily routine.

Continue performing the exercises even when they do not show any noticeable results.

Perform the exercises during vacation and while traveling.

Perform the exercises in the sitting position.

Perform the exercises in the standing position.

Contract PF before coughing, sneezing, or strongly laughing to prevent leakage.

Continue performing the exercises even when your personal and familial responsibilities are more demanding than usual.

Continue performing the exercises even when you have more activities to do than usual.

Continue performing the exercises even when you have another health problem that is more urgent.

Perform the exercises even when other people say they are unnecessary (e.g., family and friends).

Now we would like to know how confident you are that...

Confidence

PFEs will prevent or ameliorate problems such as leakage or prolapsed bladder/uterus.

PFEs will improve your sex life.

PFEs will improve your bodily perceptions.

PFEs will benefit your health and well-being. 